\title{
Reflex Seizures Triggered by Diaper Change in Dravet Syndrome
}

\author{
Ahmed H. Subki, Aishah S. Alasmari, Fadi M. Jan, Feras A. Moria, \\ Mohammed M. Jan
}

\begin{abstract}
Dravet syndrome (DS) is a severe epilepsy syndrome characterized by early onset of multiple types of seizures. We report the first case of reflex seizures triggered by diaper change in a girl at 9 months old and 2 years old with a mutation in the SCN1A gene causing DS. Reflex seizures have been reported in patients with DS provoked by increased body temperature or visual stimulation. The case we report widens the spectrum of triggers causing reflex seizures in children with DS. Cortical hyperexcitability resulting from the genetic defect explains the tendency to experience such reflex seizures.
\end{abstract}

RÉSUMÉ: Épilepsie reflexe déclenchée par un changement de couche dans le syndrome de Dravet. Le syndrome de Dravet (SD) est un syndrome épileptique sévère caractérisé par un début précoce de plusieurs types de crises d'épilepsie. Nous rapportons le premier cas de crises d'épilepsie déclenchées par un changement de couche chez une fillette alors qu'elle était âgée de 9 mois et de 2 ans. Elle est porteuse d'une mutation du gène SCN1A responsable du SD. Des crises d'épilepsie réflexe, provoquées par une augmentation de la température corporelle ou par la stimulation visuelle, ont été rapportées chez des patients atteints du SD. Le cas que nous rapportons élargit le spectre des déclencheurs causant des crises d'épilepsie réflexe chez les enfants atteints du SD. Une hyperexcitatilité corticale résultant du défaut génétique explique la tendance à présenter de telles crises.

Keywords: Epilepsy, Epilepsy - pediatric, Reflex, Dravet, Syndrome, Diaper, Seizures, Trigger

doi:10.1017/cjn.2015.394

Can J Neurol Sci. 2016; 43: 585-587

Dravet syndrome (DS) is an epileptic encephalopathy with febrile seizures that begins in infancy followed by intractable epilepsy with multiple seizure types. ${ }^{1}$ Psychomotor development is initially normal, with subsequent cognitive decline. Genetic mutations have been discovered but no genotype-phenotype correlation has been found, suggesting a multifactorial syndrome. ${ }^{2}$ Interplay among the environment, modifier genes, and epigenetics is postulated. SCN1A gene mutations are found in the majority of children with DS (80\%). PCDH19 gene mutation is found in $5 \%$ of DS children. Additionally, the rest $(15 \%)$ have neither mutation; therefore, negativity of genetic testing does not preclude a clinical diagnosis of DS.

Reflex seizures refer to recurrent focal, myoclonic, or generalized seizures that are evoked by a specific internal or external environmental stimulus as summarized in Table $1{ }^{4}$ This should be distinguished from general seizure precipitant, such as hormonal change, electrolyte imbalance, state of alertness, and fever, which are common triggering factors lowering the epileptogenic threshold. The most commonly reported seizure precipitant is elevated body temperature, whether caused by fever, warm bath, ambient warmth, or physical exercise. ${ }^{5}$ Less common external precipitants include intermittent lights, visual patterns, or music.
Reflex seizures usually occur in addition to spontaneous random seizures; here we report a patient with DS and reflex seizures triggered by diaper change.

\section{Case Report}

A 2-years-and-9-months-old girl came to our attention at the age of 15 months with a history of intractable epilepsy and intellectual disability. She was a product of full-term pregnancy and uncomplicated delivery, and was previously well with no history of trauma or meningitis. The parents were cousins with one other healthy child and no similar family history of epilepsy or other neurological disease. Her early psychomotor development was apparently normal, but slowed down from the age of 1 year. Her seizures started at age 8 months when she began to have recurrent right-sided tonic seizure with up-rolling of the eyes and cyanosis lasting for few minutes, followed by drowsiness and sleep. The seizures occurred with increasing frequency and occasionally also involved the left side of the body.

The mother noticed that some of the seizures are triggered by illness, fever, or by changing her diaper. These seizures usually started a few seconds after the beginning of changing her diaper

From the Department of Pediatrics, King Abdulaziz University, Jeddah, Saudi Arabia.

Received July 20, 2015. Final Revisions Submitted December 2, 2015.

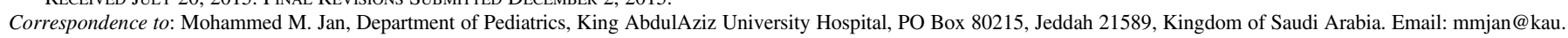
edu.sa 
Table 1: Reflex seizures and various precipitating stimuli ${ }^{4}$

\begin{tabular}{|c|c|c|c|c|}
\hline \multicolumn{2}{|l|}{ Stimulus } & \multicolumn{2}{|l|}{ Type/subtype } & Examples \\
\hline \multirow[t]{9}{*}{ Extrinsic } & \multirow[t]{4}{*}{ Somatosensory } & \multirow[t]{2}{*}{ Exteroceptive } & Simple & Tapping, touch, tooth-brushing epilepsy \\
\hline & & & Complex & Hot water epilepsy \\
\hline & & \multirow[t]{2}{*}{ Proprioceptive } & Simple & Movements, eye movements, micturition, and paroxysmal kinesigenic choreoathetosis epilepsy \\
\hline & & & Complex & Eating epilepsy \\
\hline & \multirow[t]{5}{*}{ Special Senses } & \multirow[t]{2}{*}{ Visual } & Simple & Photosensitive, pattern-sensitive, fixation-off, and scotosensitive epilepsy \\
\hline & & & Complex & Language-induced, reading, graphogenic epilepsy \\
\hline & & \multicolumn{2}{|c|}{ Auditory and vestibular } & Audiogenic, musicogenic, vestibular, singing, telephone-induced epilepsy \\
\hline & & \multicolumn{2}{|l|}{ Olfactory } & Epilepsy induced by smell \\
\hline & & \multicolumn{2}{|l|}{ Gustatory } & Eating (taste-induced) epilepsy \\
\hline Intrinsic & \multicolumn{3}{|c|}{ Complex mental processes } & Thinking (noogenic), decision-making, epilepsia arithmetica (mathematica), emotional, and startle epilepsy \\
\hline
\end{tabular}

and starting to wipe her genital area with a cloth soaked with warm water. The father recorded a video of one of these seizures, which was induced during a diaper change. She was clearly awake and interactive while lying comfortably on her back for the diaper change. Once the mother started wiping and cleaning her, she became distraught and poorly responsive, followed by head and eye deviation to the right side and by right arm posturing. The diaper change was stopped immediately and the child went on to have clonic jerking of the arm, head, and face lasting for less than 1 minute. She woke up afterward but seemed drowsy. These seizures occurred consistently with each diaper change, depending on the state of seizure control.

The seizures were poorly controlled on multiple antiepileptic drug trials that included valproic acid, clonazepam, carbamazepine, topiramate, and levetiracetam. She had four prior hospital admissions for investigation and management of seizure worsening and received, on one occasion, an intravenous pulse of methylprednisolone with temporary improvements. Detailed metabolic workup and brain magnetic resonance imaging scans were unremarkable. Interictal electroencephalograph showed intermittent focal spikes and spikeand-wave discharges maximally involving the left frontal head region (F3, F7). Given this history, we suspected the diagnosis of DS, which was confirmed by a positive deletion involving the SCN1A gene. Subsequently, the child was referred to a higher epilepsy tertiary care center for possible treatment using the ketogenic diet.

\section{DiscuSSION}

In DS, seizures can be spontaneous, facilitated, or reflex. ${ }^{6}$ Reflex seizures occur when the precipitating factor consistently and promptly elicit the seizures. In our case, the latency between changing the diaper and the seizure was consistently ultra short (seconds), as indicated by our recordings and that the seizures were reproducible. Being objectively and consistently evoked by a specific afferent stimulus suggests that they were reflex in nature. Various triggers of reflex seizures have been reported in DS, including fever, bathing in hot water, flickering sunlight, striped patterns, music, fatigue, stress, and physical exercise. In our patient, wiping a restricted area of the skin with a warm cloth induced the seizures. This occurred without pouring water on the whole body or bathing. In their minds, the parents linked the seizures to the diaper change, while it was actually related to applying the warm wipes to the genital area. This has not been previously reported in the literature.

Other authors highlighted the threat of elevated body temperature in general as a seizure precipitant in DS, whether caused by fever or hyperthermia; a warm bath was reported by up to $60 \%$ of parents. ${ }^{7}$ However, none reported seizures when warm wipes were applied to a restricted area of the skin, such as in our case. This may suggest a lowered seizure threshold because these seizures occurred with increased frequency at the times of poor or worsened seizure control. The other possibility is using water with a higher temperature. In fact, hot (rather than warm) water baths as a seizure precipitant were most frequently reported in Japanese children with DS, who are bathed at a water temperatures exceeding $39^{\circ} \mathrm{C} .^{8}$ The final possible factor explaining the reflex seizures in our patient is the higher environmental temperature in our region of Saudi Arabia. Seizures induced only by environmental heat have been reported in patients with DS. ${ }^{9}$ In addition to the application of warm wipes to the genital area, this may add further to the internal temperature and explain the increased reflex seizure tendency.

The pathophysiological mechanisms of how increased temperature provokes seizures in patients with DS are not fully known. It is speculated that the alterations in the SCN1A gene and associated reduction of the sodium currents in inhibitory GABAergic interneurons are responsible. This is crucial in the control of cortical hyperexcitability, which leads to increased seizure tendency and fever provocation. These seizures have the tendency to abate with age, suggesting a protective effect of ongoing neuronal myelination. ${ }^{10}$ Our case further broadens the spectrum of reflex seizures experienced by patients with DS. Therefore, parents and physicians should recognize factors related to seizure provocation in children with DS and provide appropriate preventative strategies and recommendations.

\section{Disclosures}

AS, AA, FJ, FM, and MJ have nothing to disclose.

\section{REFERENCES}

1. Dravet C, Bureau M, Oguni H, Fukuyama Y, Cokar O. Severe myoclonic epilepsy in infancy: Dravet syndrome. Adv Neurol. 2005;95:71-102. 
2. Dravet C, Bureau M, Bernardina BD, Guerrini R. Severe myoclonic epilepsy in infancy (Dravet syndrome) 30 years later. Epilepsia. 2011;52:1-2.

3. Dravet C. The core Dravet syndrome phenotype. Epilepsia. 2011; 52:3-9.

4. Panayiotopoulos CP. Reflex seizures and reflex epilepsies. In: The epilepsies: seizures, syndromes and management. Oxfordshire, UK: Bladon Medical Publishing; 2005.

5. Desnous B, Goujon E, Bellavoine V, Merdariu D, Auvin S. Perceptions of fever and fever management practices in parents of children with Dravet syndrome. Epilepsy Behav. 2011;21:446-8.

6. Bureau M, Dalla Bernardina B. Electroencephalographic characteristics of Dravet syndrome. Epilepsia. 2011;52:13-23.
7. Takayama R, Fujiwara T, Shigematsu H, Imai K, Takahashi Y, Yamakawa $\mathrm{K}$, et al. Long-term course of Dravet syndrome: a study from an epilepsy center in Japan. Epilepsia. 2014;55: 528-38.

8. Oguni H, Hayashi K, Awaya Y, Fukuyama Y, Osawa M. Severe myoclonic epilepsy in infants-a review based on the Tokyo Women's Medical University series of 84 cases. Brain Dev. 2001;23:736-48.

9. Ceulemans B. Overall management of patients with Dravet syndrome. Dev Med Child Neurol. 2011;53:19-23.

10. Ragona F, Brazzo D, Giorgi ID, Morbi M, Freri E, Teutonico F, et al. Dravet syndrome: early clinical manifestations and cognitive outcome in 37 Italian patients. Brain Dev. 2010;32:71-7. 